\title{
Evaluation of otolith shape as a tool for stock discrimination in marine fishes using Baltic Sea cod as a case study
}

Hüssy, Karin; Mosegaard, Henrik; Albertsen, Christoffer Moesgaard; Eg Nielsen, Einar; Hansen, Jakob Hemmer; Eero, Margit

\section{Published in:}

Fisheries Research

Link to article, DOI:

10.1016/j.fishres.2015.10.010

Publication date:

2016

Document Version

Peer reviewed version

Link back to DTU Orbit

Citation $(A P A)$ :

Hüssy, K., Mosegaard, H., Albertsen, C. M., Eg Nielsen, E., Hansen, J. H., \& Eero, M. (2016). Evaluation of otolith shape as a tool for stock discrimination in marine fishes using Baltic Sea cod as a case study. Fisheries Research, 174, 210-218. https://doi.org/10.1016/j.fishres.2015.10.010

\section{General rights}

Copyright and moral rights for the publications made accessible in the public portal are retained by the authors and/or other copyright owners and it is a condition of accessing publications that users recognise and abide by the legal requirements associated with these rights.

- Users may download and print one copy of any publication from the public portal for the purpose of private study or research.

- You may not further distribute the material or use it for any profit-making activity or commercial gain

- You may freely distribute the URL identifying the publication in the public portal 
Evaluation of otolith shape as a tool for stock discrimination in marine fishes using Baltic Sea cod as a case study

Karin Hüssy*, Henrik Mosegaard, Christoffer Moesgaard Albertsen, Einar Eg Nielsen, Jakob Hemmer-Hansen, Margit Eero

\section{PUBLISHED AS:}

Hüssy, K., Mosegaard, H., Albertsen, C.M., Nielsen, E.E., Hemmer-Hansen, J., and Eero, M., 2016. Evaluation of otolith shape as a tool for stock discrimination in marine fishes using Baltic Sea cod as a case study Fisheries Research, 174: 210-218.

AVAILABLE AT: http://dx.doi.org/10.1016/j.fishres.2015.10.010

National Institute of Aquatic Resources, Technical University of Denmark, Jaegersborg Alle 1, 2920 Charlottenlund, Denmark

*Corresponding Author: tel: +45 3588 3458; fax: +45 3588 3333; e-mail: kh@aqua.dtu.dk 
Abstract

In the Western Baltic Sea two genetically distinct cod stocks "Eastern Baltic cod" and "Western Baltic cod" occur with considerable mixing of stocks. In this study we evaluated the applicability of otolith shape analysis for classification of individuals caught in the mixed stock cod fishery, using SNP (Single nucleotide polymorphism) based genetic assignment of otolith shape baselines. We further developed a management aimed approach for mixed stock assignment by robust stochastic baseline selection and posterior bias correction by individual reassignment of the least likely classifications into the alternate stock. Classification criteria selected by Monte Carlo runs of Linear Discriminant Analysis were captured by otolith area and 20 Elliptic Fourier Descriptors of primarily low frequency harmonics. Classification success was considerably lower when using a baseline of spawning individuals only, compared to the better spatial coverage of a combined baseline also including genotyped individuals from the mixed stock area. Furthermore, the inclusion of genotyped individuals balanced the baseline size composition and to a large extent removed a strong size related bias in classification success. These results demonstrate the interplay of environmental, ontogenetic and genetic influences on otolith shape, which complicates the application of otolith shape for stock discrimination in mixed-stock scenarios. Rigours genetic validation and further studies on the temporal dynamics of shape formation are necessary.

Key words: Baltic Sea; cod; genetic validation; otolith shape; stock discrimination 


\section{Introduction}

The stock concept is one of the most fundamental in fishery management. With the development of new analytical methods, an ever increasing number of studies have documented the existence of biocomplexity (Ruzzante et al. 2006) with discrete populations within areas previously considered, and managed, as representing a single stock. Mechanical mixing of populations, with limited interbreeding, may result from an overlap in distribution range (Edmonds et al., 1989), for example due to seasonal spawning/feeding migrations (Johnson et al., 1994; Campana et al., 1999, 2000 and 2007; Ruzzante et al., 2006). Failure to take stock mixing into account in fisheries management, particularly when the stocks differ in productivity, may lead to sub-optimal exploitation and ultimately over-fishing of some stock components (Begg et al., 1999; Heath et al. 2013). Therefore, efficient stock discrimination methods are needed.

A suite of analytical techniques have been used for stock discrimination, ranging from morphometrics (Elliott et al., 1995) and parasite loading (Braicovich and Timi, 2008) over conventional tagging (Lear, 1984), otolith microstructure analysis (Mosegaard and Madsen, 1996) and otolith microchemistry (Campana et al., 2000, 2007) to molecular tools (Johnson et al., 1994; Ruzzante et al., 1999, 2006; Nielsen et al., 2012) and otolith shape analyses (Campana and Cassleman, 1993). Owing to the higher expenses associated with molecular tools, in combination with the availability of otolith samples from extensive historical archives in fisheries research institutes, otolith shape analysis has recently gained interest among fisheries biologists. Otolith shape is known to depend on a combination of genetic and environmental factors (Cardinale et al., 2004) and separation of populations in both time and space induces divergent otolith shape patterns (Messieh, 1972; Lombarte and Lleonart, 1993). Consequently, otolith shape analyses can be a powerful tool for fish stock management purposes, and is already implemented in stock assessment for example for North Sea herring (ICES, 2013a). The primary analytical tool used for spatial and 
temporal discrimination of stocks and populations (e.g. Bolles and Begg, 2000; Cardinale et al., 2004, Mérigot et al., 2007) has been based on the Fourier Series Shape Analysis (Bird et al. 1986), and has been applied for various species, such as cod and herring. For cod, most of the previous studies were designed to map the geographical distribution of populations and/or stock components in the Northwest Atlantic (Campana and Cassleman, 1993), the Northeast Atlantic (Stransky et al., 2008), Iceland (Jónsdottir et al., 2006; Petursdottir et al., 2006), Scotland/Ireland (Galley et al., 2006) and the Baltic Sea (Paul et al., 2013). The objectives of these studies were to evaluate the impact of genetic and/or environmental conditions on otolith shape and their usefulness as stock discrimination tool. Even though these studies found highly significant differences in otolith shape when comparing cod captured in their spawning areas, none of them have addressed the application of this approach for management purposes in an area with mixed stocks. In this study, the applicability of otolith shape analysis for the identification and estimation of stock proportions in management situations where biological populations mix (i.e. a mixed stock scenario) is examined using the example of Baltic Sea cod.

Cod are generally distributed throughout the Baltic Sea (Bagge et al., 1994), and is assessed and managed as two distinct populations, one east of the island of Bornholm (ICES Subdivisions (SD) 25-32), the other from west of Bornholm to the Sound and the Danish Belts (ICES SDs 22-24) (Fig. 1). The two populations differ with respect to morphometric characteristics as well as genetic variation (Bagge et al., 1994; Nielsen et al. 2003, 2005). However, as part of their seasonal cycle, adult cod, for example in the Arkona Basin (SD 24) undertake distinct and highly complex migrations, targeting specific feeding and spawning areas which may cross management and environmental boundaries (i.e. into SD 25) (Aro, 1989; Berner and Borrmann (1985) Berner, 1967; Otterlind, 1985 ). Spawning migrations of cod tagged east of Bornholm (SD 25) to the Arkona Basin (SD 24) also occur (Aro, 1989; Nielsen et al., 2013). These studies suggest that eastern and western 
Baltic cod stocks co-occur in the Arkona Basin (SD 24). Thus, interactions between populations in the western Baltic Sea are highly dynamic and provide a valuable scenario for assessing methods for stock discrimination under complex scenarios of relevance to fisheries management. The abundance of eastern Baltic cod in SD 25 has substantially increased in recent years (Eero et al., 2012a), while that of the western Baltic cod in SD 22 is low (ICES, 2013b). A relatively high abundance of cod currently found in SD 24, belonging to the management area of the western cod, is considered to be due to spill-over of the eastern cod (Eero et al. 2014; ICES, 2013b). In order to be able to account for this stock mixing in fisheries management to avoid depletion of the cod of western origin, an efficient stock discrimination tool is needed.

The objective of this paper is to evaluate otolith shape as a methodology for stock discrimination in an area with potential mixing of two neighbouring stocks. This evaluation relies on validation through genetic assignment and includes a general evaluation of the traditional otolith shape analysis setup as well as an assessment of the impact that the selection of baseline samples has on the applicability of this method to the mixed stock. Since management does not need correct individual classification but rather relies on unbiased and precise estimates of proportions of each stock, classifications were statistically corrected to reflect the true underlying proportions and the conditions for optimal selection of baselines were analysed.

2. Materials and methods

The otolith shape based stock discrimination relies on the definition of stock-specific otolith shapes derived from baseline reference samples consisting of individuals known to belong to a specific stock. Otolith shapes as silhouette outlines from these baseline samples are extracted from digitised images using image processing techniques and parameterised through Elliptic Fourier Analysis 
(EFA) to derive stock classification criteria by Linear Discriminant Analysis. In this study we used two different types of baselines, one based on the traditional "spawning stock" baseline (see section 2.1.) and one also including all genotyped individuals from the mixed stock area, the "combined" baseline (see section 2.2.). The performance of the two baselines was tested by comparison of otolith shape based classifications with genetically identified stock of origin in a mixed stock sample.

\section{1. Samples for "spawning stock" baseline}

For each stock, individuals were collected on the known spawning grounds during the spawning season in 2011 (Fig. 1). For eastern Baltic cod the only spawning area with hydrographic conditions suitable for egg survival is the Bornholm Basin (SD 25), with a spawning season from May to September (peak spawning season June/July). The main spawning grounds of the western Baltic cod are the Kiel Bay and the Danish Straits (SD 22) where the main spawning season is restricted to March/April. In the Arkona Basin (SD 24), efforts were made to cover both the Eastern and Western stocks' main spawning season, but spawning individuals were only found in May/June and none in March/April. Samples were collected from scientific research cruises and from market sampling. Each fish was identified with an individual number and standard biological data were collected (total length, sex, maturity stage). Only individuals with maturity stages 4 - 6: "late spermatogenesis" to "spawning" (Tomkiewicz et al., 2003) were selected in order to ensure that the "true" spawning stocks within an area were selected. These samples are referred to as "spawning stock" baseline (Table 1, Fig. 2). As age estimation of the eastern Baltic cod stock is highly unreliable (Hüssy, 2010), age information was not included in any of the analyses below.

\section{2. Samples for "combined" baseline}

The samples collected in SD 24 in June 2011 consisted of both spawning and non-spawning individuals, subsamples of which were also selected for genetic stock identification (Table 1, Fig. 2). 
For each fish, a sample of fin-clip tissue was preserved in an Eppendorf vial filled with ethanol. Otoliths were removed and stored in paper bags following standard procedures.

For genetic assignment, a panel of 39 single nucleotide polymorphism (SNP) markers identified to be particularly powerful for separating eastern (SD 25) and western (SD 22) Baltic Sea populations were used (see Nielsen et al. 2012 for concept). Genetic baselines were established based on spawning individuals of eastern and western Baltic cod captured on their respective spawning grounds in SD25 and 22. Each individual of the mixed stock in SD 24 was assigned to biological population (east or west) through a Bayesian approach (Rannala and Mountain 1997) implemented in the programme GeneClass (Piry et al. 2004). Of 754 genotyped individuals 746 individuals could unambiguously be assigned to either the eastern or western Baltic cod stock. Eight individuals had assignment probabilities of $<0.98$ and were excluded from the dataset.

Together, these samples formed a baseline sample consisting of individuals from a broader size range and all areas under investigation. Consequently, this setup potentially includes a larger variation in otolith shapes within the two groups compared to the "spawning stock" baseline. Based on the finding that all spawning individuals in the western (SD22) and eastern (SD25) regions were genetically assigned to their population of origin, a "combined" baseline was constructed by merging the "spawning stock" baseline and all genotyped individuals to utilise the full baseline potential of all individuals with known stock affiliation.

\section{3. Otolith contour capture}

The otolith contours of all 3209 cod were captured. Otoliths were viewed under a Leica MZ12 microscope equipped with a circular reflected light source and a magnification of $15 \mu \mathrm{m} \cdot \mathrm{pixel}^{-1}$. Images of otoliths were digitised with a Leica DFC290 camera and a standard setup (8 bit/channel, 2048 x 1536 pixel frame, $35 \mathrm{~ms}$ exposure). In order to standardise otolith orientation, all otoliths were placed with the sulcus facing up as pairs in the same position (left otolith on the left and the 
rostrum towards the top of the image). Images were stored as JPG files. We used the MATLAB (C) "snake" contour finding function to localise the closed 2D curve minimising the curvature energy following the pixels identified as the border in the black and white transformed image using a calibrated light saturation level between the light otolith and the dark background. Thus the identified contours consisted of a sequence of $x$ - and $y$-coordinates smoothly tracking the edge of each individual otolith (Haines and Crampton, 2000).

Elliptic Fourier Descriptors (EFDs) were fit to the contours of each individual otolith. The coefficients were then made invariant to starting point, scale (length of major axis) and rotation. The standardised $\mathrm{x}-\mathrm{y}$ coordinates are represented by:

$x_{p}=\sum_{i=1}^{60}\left(A_{i} \cos \frac{2 i \pi t_{p}}{T}+B_{i} \sin \frac{2 i \pi t_{p}}{T}\right)$

$y_{p}=\sum_{i=1}^{60}\left(C_{i} \cos \frac{2 i \pi t_{p}}{T}+D_{i} \sin \frac{2 i \pi t_{p}}{T}\right)$

Where $A_{i}, B_{i}, C_{i}$ and $D_{i}$ are the standardised EFDs for frequency components $i=1,2, \ldots, 60$, and $A_{1}$ $=1, B_{1}=0$ and $C_{1}=0$ and omitted from any discrimination analysis. Further, $T$ is the total length of the perimeter, $\mathrm{x}_{p}$ is the $\mathrm{x}$-coordinate of point $p, \mathrm{y}_{p}$ is the $\mathrm{y}$-coordinate of point $p$, and $t_{p}$ is the length of the perimeter from the starting point until point $p$ defining the continuous contour as piecewise straight lines between succeeding contour points (Kuhl and Giardina, 1983). The procedure was set to result in $i=60$ harmonics.

Based on the predictor values of a few highly indicative EFDs, each otolith was identified as either right or left. Since there is no systematic difference between right and left otolith in cod (Cardinale et al., 2004) only the largest otolith of each pair was selected for the subsequent analyses to avoid bias 
induced by chipped edges. If the larger otolith happened to be the right otolith, the MATLAB routine involved flipping the image and recalculating the EFDs to result in left hand contours only. The EFDs were for each of the two baselines ("spawning stock" and "combined") standardised in relation to fish length as the residuals of the linear relationship $\mathrm{EFD}_{\mathrm{i}}=\mathrm{a}+\mathrm{b} \cdot \mathrm{L}$ estimated for the entire dataset, and not a separate regression for each of the two stocks. Within group standardisation (i.e. Paul et al., 2013) was avoided since this method cannot be used on the mixed stock samples where individual stock affiliation is unknown for the test sample and individual stock specific residuals thus cannot be calculated. Balanced subsets were selected by stratified random sampling of the total baseline to select the most robust descriptors for classification. The subsets were stratified into four length groups with group length intervals set to ensure at least 10 individuals within each size group of the baseline sample (Table 2). The resulting four size groups were $<32 \mathrm{~cm}, 32-39 \mathrm{~cm}, 40-47$ $\mathrm{cm}$ and $\geq 47 \mathrm{~cm}$. This length stratification ensured a selection of random baseline subsets as calibration samples with all length classes present in constant proportions for further Linear Discriminant Analyses.

\section{4. Discriminant analysis}

The Discriminant Analysis was carried out as two separate analyses, one with the "spawning stock" baseline and one with the "combined" baseline. To identify the descriptors with the highest discrimination power between stocks a forward-backwards stepwise Linear Discriminant Analysis (SAS PROC STEPWISE) was run 100 times on random subsets of the two baseline samples (Table

2) and the 21 overall most frequent descriptors were selected as a robust variable list for all further analyses.

In order to estimate each individual's probability of belonging to either of the two stocks, a series of 100 LDAs on randomised baseline subsets was subsequently carried out (SAS PROC DISCRIM). PROC DISCRIM develops a classification criterion by using a measure of generalized squared 
distance. The LDA classification criterion was based on the pooled covariance matrix. Each observation $x$ was placed in the stock $S$ from which it had the smallest generalized squared Mahalanobis distance, $D^{2}$. According to Bayes theorem PROC DISCRIM also computed the posterior probability of an observation belonging to each class under the assumption that predictors follow a multivariate normal distribution.

$p(S \mid x)=\frac{\exp \left(-0.5 D_{S}^{2}(x)\right)}{\sum_{u} \exp \left(-0.5 D_{u}^{2}(x)\right)}$

An observation is classified into group $u$ if setting $S=u$ produces the largest value of $p(S \mid x)$ or the smallest value of $D_{S}^{2}(x)$, using flat priors for the two groups.

\section{5. Application to mixed stock}

"Spawning stock" baseline: The stock-specific discrimination functions based on the 21 descriptors with the highest discrimination power derived from the "spawning stock" baseline analyses were applied to the mixed stock otolith contours (SD 24).

A posterior probability for each otolith of belonging to either of the two stocks $S$ (SD 22 or 25) was calculated using equation (2). From these probabilities the one with the highest value was selected as the individual's stock affiliation. Genotype and otolith shape based stock assignments were compared for all individuals captured in SD 24.

"Combined" baseline: The analyses based on the "combined" baseline were carried out by random selection of a subset of samples from the baseline as calibration sample (Table 2), with the remaining samples of the baseline serving as test sample. The identified list of 21 descriptors was applied in 100 runs of Linear Discriminant Analysis (LDA). In each run the baseline observations within each length group were randomly divided into two subsets of constant size, the first acting as the calibration sample (Table 2), and the second with the remaining observations in the baseline serving as a test sample with known stock affiliation. 
During the LDA procedure each observation was classified into the most probable stock according to equation (2). If the observation was part of the calibration sample the "leave one out" crossvalidation method was applied; if the observation was part of the test sample the cross-validated discriminant function estimated for the calibration sample was used. The average probability of stock affiliation was calculated for both the calibration cases and the test cases for each observation. There was no difference between the cross-validation and random test sample methods of calculating classification success.

\subsection{Correction of bias in classification}

Knowing each individuals true stock affiliation, the 100 re-samplings also allowed the estimation of bias and error of the otolith derived stock classifications. From the stratified random test sample LDA, the probability of correctly classifying individuals from the eastern and western stock respectively was estimated. Then corrected estimates of the mixing proportions were calculated by solving the equations

$C_{W}=M_{W \mid E} P_{E}+M_{W \mid W} P_{W}$

and

$C_{E}=M_{E \mid E} P_{E}+M_{E \mid W} P_{W}$

for $P_{E}$ and $P_{W}$. Here $P_{E}$ is the unbiased proportion from the eastern stock, $M_{E \mid E}$ is the probability of classifying an individual from the eastern stock to the eastern stock, $M_{E \mid W}$ is the probability of classifying an individual from the western stock to the eastern stock, and $C_{E}$ is the proportion classified to the eastern stock. The subscript $W$ indicates the similar variables for the western stock. With known $\mathrm{M}_{\mathrm{E} \mid \mathrm{E}}$ and $\mathrm{M}_{\mathrm{W} \mid \mathrm{W}}$ the equations yield the unbiased corrected proportion estimates $\hat{P}_{W}=\frac{M_{E \mid E} C_{W}-M_{W \mid E} C_{E}}{M_{W \mid W} M_{E \mid E}-M_{E \mid W} M_{W \mid E}}=\frac{C_{W}-M_{W \mid E}}{1-M_{E \mid W}-M_{W \mid E}}$ and 
$\hat{P}_{E}=\frac{M_{W \mid W} C_{E}-M_{E \mid W} C_{W}}{M_{W \mid W} M_{E \mid E}-M_{E \mid W} M_{W \mid E}}=\frac{C_{E}-M_{E \mid W}}{1-M_{E \mid W}-M_{W \mid E}}=1-\hat{P}_{W}$

$\hat{P}_{E}$ is only defined for $M_{E \mid W}+M_{W \mid E} \neq 1$. When $M_{E \mid W}+M_{W \mid E}=1$, equation (3) has no solutions. In this case it is, however, possible to find an estimate of $\hat{P}_{E}$ by e.g. least squares. In theory, if there is a high probability of misclassification, the correction procedure may yield a negative estimate. The negative estimate is then set to zero, and the other estimate is set to one. However, this was not the case with the present estimates.

The relative bias $\hat{b}_{S}$, of a given stock assignment $S$, may be estimated as the proportion of noncorrected assignment to corrected assignment minus one,

$\hat{b}_{S}=\frac{c_{S}}{\hat{P}_{S}}-1$

and vice versa for the compliment stock $\backslash S$.

Sustainable fisheries management relies on correct actions on relevant population units (Reiss et al. 2009). Assessment of mixed stocks requires unbiased estimates of stock proportions and the practical data management often relies on individual assignment to calculate proportions at different aggregation levels. To implement bias correction at this level, an individual based reassignment was therefore implemented where the individuals with the lowest stock classification probability, $p(S \mid x)$ (equation (2)) were moved to the complement stock before the subsequent estimation of population dynamics at any chosen aggregation level. In the cases where classification to stock $S$ exhibited a positive $\hat{b}_{S}, n_{S}$ individuals were reassigned to the complement stock $\backslash S$, to yield a data set with unbiased stock proportions, calculating $n_{S}=\left(\hat{P}_{S}-C_{S}\right) \times N_{L, y}$, where $N_{L, y}$ is the number of individuals from both stocks of length group L in year y. Stock assignment was then shifted for the $n_{S}$ individuals with the lowest ranked probability of affiliation to $S$, and the posterior assignment success was calculated for both stocks. 


\section{Results}

\subsection{Self-assignment success of "spawning stock" baseline}

Traditionally, results of otolith shape based stock discrimination include the cross-validated classification success of the two samples. Most significant descriptors discriminating between the two stocks were otolith area, followed by EFD's from low-frequency harmonics where the significant EFD's occurring most frequently in the 100 runs were: D5, C5, D7, B2, X10, D4, D1, A13, B9 and C6. This indicates that the otolith shapes from the two stocks differ in the large scale shape characteristics, particularly the length - width relationship where otoliths from the western stock are wider and rounder than those from the eastern stock (Fig. 3). For comparison with other studies these results are shown in Table 3. Owing to the large difference in size distribution of the spawning components between the two stocks, it was not possible to entirely remove the size effect through standardisation of the residuals and the size - balanced baseline. This problem is evident in the low classification success of the small size groups of the eastern stock and largest size group of the western stock. The low sample sizes of western cod in the smaller size groups is further reflected in the large bias.

\section{2. Discrimination of mixed stock based on "spawning stock" baseline}

Of the 746 genotyped individuals within SD 24 only 65 were western Baltic cod. The otolith shape based classification of the "spawning stock" baseline on the mixed stock samples from SD 24 was validated by comparison of otolith shape classifications with assigned genotypes of each individual. The genetically validated classification results show a size-related trend in classification success, in particular for the western genotype, with only approximately $80 \%$ in the two size groups $>40 \mathrm{~cm}$ but $100 \%$ in the smaller fish (Table 4). In the eastern genotype classification was generally lower, and 
the size-related trend was reversed, with as little as $21 \%$ successful classification in $<32 \mathrm{~cm}$ cod and only $87 \%$ in the largest size group (Table 4 ).

\section{3. Discrimination of mixed stock based on "combined" baseline}

Also in this approach, otolith area and EFDs from low-frequency harmonics indicate stock-specific otolith shape differences with respect to the otolith length - width relationship. The significant descriptors occurring most frequently in the 100 runs were: Otolith area, D7, D5, D3, D1, C8, C6, B3, C11, A4, A6, B4, C3, A11, C2, D12, C13 and B10. The genetically validated classification success based on the "combined" baseline was overall considerably higher than for the "spawning stock" baseline (Table 4). This improvement of classification success was particularly evident for the eastern stock, where values increased from $21-87 \%$ for the "spawning stock" baseline to $75-96 \%$ when using the "combined" baseline. For western Baltic cod, the increase in classification success based on the "combined" baseline was somewhat smaller.

Bias decreased from $36-965 \%$ in the western stock to $0-271 \%$ and from $-9--79$ to $0--24 \%$ in the eastern stock. Given the higher success rate and lower numbers of the western stock samples relative bias was generally positive and in absolute terms larger than for the eastern stock samples. Easter Baltic otoliths have thus a higher risk of being assigned as western Baltic cod than the opposite. The classification success for each cod based on the "combined" baseline is shown as a function of Canonical Discriminant value (averaged over 100 runs) in relation to fish size (Fig. 4).

Bias correction was applied to yield unbiased stock proportions within length groups by reassigning stock membership for the required number of individuals within the classified stock that had a positive bias, thus for test purposes individuals were reassigned from the western to the eastern stock in all the three smallest length groups, whereas no individuals were reassigned for the largest length group where no bias was found. The otoliths with the lowest probabilities of individual stock affiliation were chosen to be reassigned and the posterior individual assignment success was 
calculated. After reassignment, classification success expectedly decreased for the western stock and increased for the eastern stock (Table 4).

\section{DISCUSSION}

This study has documented the applicability of otolith shape characteristics to discriminate Baltic cod stocks collected in the spawning areas. We also identified significant challenges when applying the method in an area with highly complex spatio-temporal mixing dynamics. In the following we will address methodological issues and provide an evaluation of the approach's applicability to discriminate individuals in a mixed stock, as well as recommendations for the development of this approach to be able to use it on a routine basis for fisheries management purposes.

The otoliths of eastern Baltic cod were generally narrower in the dorso-ventral direction in relation to the anterior-posterior length than those of western Baltic cod. This seems to be an inherent trait of the two Baltic cod stocks already reported by Berner (1968). Also other cod stocks can be discriminated based on their otolith's circularity and rectangularity (Begg and Brown, 2000; Bolles and Begg, 2000; Begg et al., 2001; Cardinale et al., 2004). Differences seem mediated by growth rate, which seems to contribute more variation to regional differences in otolith shape than stock of origin (Campana and Casselman, 1993). The "growth effect" is a well-known phenomenon in the otolith - fish growth dynamics and is manifested by slow growing fish having a larger otolith size than fast growing fish at similar fish size, because otoliths continue to grow even though the fish is starving or growing poorly (i.e. Mosegaard et al. 1988, Reznick et al., 1989; Secor and Dean, 1989). However, the growth effect's impact on otolith shape is not entirely clear. While slower growth entrains longer and wider otoliths in silver hake (Bolles and Begg, 2000) it leads to narrower otoliths in haddock (Begg and Brown, 2000) and Faroe Plateau cod (Cardinale et al., 2004). Consequently, discrimination power between stocks increases with increasing differences in growth rate (Campana 
and Cassleman, 1993). Growth rates of the eastern and western Baltic cod have historically differed considerably resulting in a mean size at age 4 of ca. $42 \mathrm{~cm}$ in the eastern and $64 \mathrm{~cm}$ in the western stock (Bagge et al., 1994). These differences in growth rates may thus be the underlying mechanisms for the observed differences in otolith shape, where the challenges with stock classification of the mixed stock samples result from a complex interaction of environmental effects and genetic background on growth rates. The deteriorating somatic condition of eastern Baltic cod triggered by decreasing prey availability in recent years (Eero et al., 2012b; 2014) may even have exacerbated the difference in otolith shape between the two stocks (Cardinale et al., 2004).

Another well-known phenomenon is the allometric nature of the otolith's length/height relationship in relation to fish size, where otoliths become wider with fish size within the same stock (Simoneau et al., 2000) including the Baltic cod (Berner, 1968). Otolith shape variables are therefore generally standardised in order to correct for possible trends related to fish size (Bolles and Begg, 2000; Cardinale et al., 2004; Jónsdóttir et al., 2006; Tracey et al., 2006). In the present study, this standardisation procedure was carried out using the slope of the entire sample and not the common within-group slopes for each sampling group separately as practised by Paul et al. (2013). The latter approach is not applicable to unknown test samples such as our analysis of the mixed stock in SD24. Further it may lead to an overly optimistic self-classification success of within-group standardised baseline categories, particularly if the samples' size distributions only overlap to a limited degree as in the present case. However, these standardization procedures are often not able to remove the size effect entirely (Campana and Casselman, 1993), as also observed in this study. In order to avoid size related bias in classification, a balanced size-stratified baseline selection is necessary to amend for that shortcoming.

The baseline sample has traditionally consisted of spawning individuals, based on the assumption of natal homing for spawning (i.e. Campana and Cassleman, 1993; Begg and Brown, 2000; Galley et al., 2006; Jónsdóttir et al., 2006). Our finding of high self-classification success of spawning 
individuals collected at spawning sites align with findings from earlier studies (Paul et al. 2013). But this procedure neglects to incorporate otolith shapes of smaller and immature individuals. The present study documented that the traditional method of using a "spawning baseline" is challenged when applied on mixed stock samples. Overall, eastern cod had a higher risk of being classified as western cod than the opposite. Furthermore, a strong size trend in classification success with low classification success in small eastern and large western cod was observed. This misclassification pattern is to some degree attributable to the fact that mature western cod are generally larger than eastern cod, with an under-representation of western cod in the small size classes. But it is primarily due to the fact that the "spawning baseline" does not cover the entire size range, thereby neglecting to incorporate an ontogenetic change in otolith shape (Bird et al., 1986). The size-related bias in classification success was alleviated when the stock discrimination analysis was based on the "combined" baseline, which incorporates smaller size classes, and eastern Baltic cod were correctly classified to a higher degree. The "combined" baseline is therefore better suited than the "spawning baseline" for stock identification of individuals in a mixed stock sample.

The genetically validated stock discrimination based on otolith shape analysis has demonstrated that for this approach to be applicable to discriminate between stocks in a mixed stock area, careful consideration should be paid to possible bias introduced by the methodology. Even though a genetically based stock discrimination may be the optimal, this option may not be available or economically feasible for all stocks and areas with mixed stocks. In such a case, a combined genetics - otolith shape approach should be applied. In order for this combined method to be applied for stock assessment purposes we recommend that the following issues should be addressed:

1. Validation of classifications: This study has highlighted the need for rigorous genetic validation of the classification results when applying otolith shape analysis to identify the stock origin of individuals within a mixed stock sample. 
2. Baseline sample: A combination of spawning stock baseline, supplemented with genotyped individuals encompassing all size and age groups should be used to alleviate size related bias on otolith shape.

3. Standardisation of Discriminant analysis: Length-based standardisation using a common regression slope and separate size groups should be used if standardisation fails to remove all size effects.

4. Correction for bias: To achieve unbiased proportions for population modelling the underlying true stock affiliation from the genotyping should be applied to correct bias where the required proportion of individuals with low classification probability should be reassigned.

5. Temporal stability in otolith shape: The present results are based on samples collected within a single year. As year-class effects on otolith shape are known to occur (Castonguay et al., 1991; Campana and Casselman, 1993; Bolles and Begg, 2000) the temporal stability of otolith shape in the baseline samples needs to be examined through genetic assignment of archived otoliths.

6. Temporal dynamics in otolith shape transition: To date, no information exists on how quickly otolith shape adapts to migration induced changes in environmental conditions. A suite of techniques to achieve this knowledge is available, including "Common garden" experiments, mark-recaptures of wild fish and analysis of otolith microchemistry to identify migration dynamics.

\section{Acknowledgements}

This study was funded by the Danish Ministry for Food, Agriculture and Fisheries and the European Union through the project "Improved management based on stock identification of eastern and 
western Baltic cod" (European Fisheries Fund: contract nr. 3744-11-k-0216). Sample collection for the baseline samples were carried on a "BALTICA" cruise which was financially supported by the Danish Centre for Marine research. We thank Dr. Bastian Huwer, Frank Ivan Hansen, Thomas Møller and Peter Vingaard Larsen for their efforts to collect samples.

\section{References}

Aro, E., 1989. A review of fish migration patterns in the Baltic. Rap. Proc. Verb. Réun. Cons. Int. Explor. Mer 190, 72-96.

Bagge, O., Thurow, F., Steffensen, E., and Bay, J., 1994. The Baltic cod. Dana 10, 1-28.

Begg, G.A., Brown, R.W., 2000. Stock Identification of Haddock Melanogrammus aeglefinus on Georges Bank Based on Otolith Shape Analysis. Trans. Am. Fish. Soc. 129, 935-945.

Begg, G.A., Friedland, K.D., Pearce, J.B., 1999. Stock identification and its role in stock assessment and fisheries management: an overview. Fish. Res. 43, 1-8.

Begg, G.A., Overholtz, W.J., Munroe, N. J., 2001. The use of internal otolith morphometrics for identification of haddock (Melanogrammus aeglefi nus) stocks on Georges Bank. Fish. Bull. $99,1-14$.

Berner, M., 1967. Results of cod taggings in the western and central Baltic in the period 1962-1965. ICES Doc. CM 1967/F: 05.

Berner, M., 1968. Einige Untersuchungen an den Otolithen des Dorsches (Gadus morhua L.) aus verschiedenen Regionen der Ostsee. Fisch. Forsch. 1, 77-86.

Berner, M., Borrmann, U., 1985. Zum saisonalen Längenwachstum des Dorsches der Mecklenburger Bucht nach Wiederfangdaten von Markierungsexperimenten und Bestandsvergleichen. Fisch. Forsch. Wissenschaftl. Schriftenr. 23, 63-69. 
Bird, J.L., Eppler, D.T., Checkley Jr., D.M., 1986. Comparison of herring otoliths using Fourier series shape analysis. Can. J. Fish. Aquat. Sci. 43, 1228-1234.

Bolle, L.J.., Begg, G.A., 2000. Distinctions between silver hake (Merluccius bilinearis) stocks in U.S. waters of the northwest Atlantic based on whole otolith morphometric. Fish. Bull. 98, $451-462$.

Braicovich, P.E., Timi, J.T., 2008. Parasites as biological tags for stock discrimination of the Brazilian flathead Percophis brasiliensis in the south-west Atlantic. J. Fish Biol. 73, 557571.

Campana, S.E., Casselman, J.M., 1993. Stock discrimination using otolith shape analysis. Can. J. Fish. Aquat. Sci. 50, 1062-1083.

Campana, S.E., Chouinard, G.A., Hanson, J.M., and Fréchet, A., 1999. Mixing and migration of overwintering cod stocks near the mouth of the Gulf of St. Lawrence. Can. J. Fish. Aquat. Sci. 56, 1873-1881.

Campana, S.E., Chouinard, G.A., Hanson, J.M., Fréchet, A., Brattey, J., 2000. Otolith elemental fingerprints as biological tracers of fish stocks. Fish. Res. 46, 343-357.

Campana, S.E., Valentin, A., Sévigny, J.-M., Power, D., 2007. Tracking seasonal migrations of redfish (Sebastes spp.) in and around the Gulf of St. Lawrence using otolith elemental fingerprints. Can. J. Fish. Aquat. Sci. 64, 6-18.

Cardinale, M., Doering-Arjes, P., Kastowsky, M., Mosegaard, H., 2004. Effects of sex, stock, and environment on the shape of known-age Atlantic cod (Gadus morhua) otoliths. Can. J. Fish. Aquat. Sci. 61, 158-167.

Castonguay, M., Simard, P., Gagnon, P., 1991. Usefulness of Fourier Analysis of otolith shape for Atlantic mackerel (Scomber scobrus) stock discrimination. Can. J. Fish. Aquat. Sci. 48, $296-302$. 
Eero, M., Köster, F.W., Vinther, M., 2012a. Why is the eastern Baltic cod recovering? Mar. Pol. 36, $235-240$.

Eero, M., Vinther, M., Haslob, H., Huwer, B., Casini, M., Storr-Paulsen, M., Köster, F.W., $2012 b$. Spatial management of marine resources can enhance the recovery of predators and avoid local depletion of forage fish. Cons. Lett. 5, 486-492.

Eero, M., Hemmer-Hansen, J., Hüssy, K., 2014. Implications of stock recovery for a neighbouring management unit: experience from the Baltic cod. ICES J. Mar. Sci. (in press)

Edmonds, J.S., Msran, M.J., Caputi, N., Moriaat, M., 1989. Trace element analysis of fish sagittae as an aid to stock identification: pink snapper (Chrysophrys auratus) in Western Australian waters. Can. J. Fish. Aquat. Sci. 46, 50-54.

Elliott, N.G., Haskard, K., Koslow, J.A., 1995. Morphometric analysis of orange roughy (Hoplostethus atlantics) off the continental slope of southern Australia. J. Fish Biol. 46, 202-220.

Galley, E.A., Pright, P.J., Gibb, F.M., 2006. Combined methods of otolith shape analysis improve identification of spawning areas of Atlantic cod. ICES J. Mar. Sci. 63, 1710-1717.

Haines, J., Crampton, J. S., 2000. Improvements to the method of Fourier shape analysis as applied in morphometric studies. Palaeont. 43, 765-783.

Heath, M.R., Culling, M.A., Crozier, W.W., Fox, C.J., Gurney, W.S.C., Hutchinson, W.F., Nielsen, E.E., O’Sullivan, M., Preedy, K.F., Righton, D.A., Speirs, D.C., Taylor, M.I., Wright, P.J., Carvalho, G.R., 2013. Combination of genetics and spatial modelling highlights the sensitivity of cod (Gadus morhua) population diversity in the North Sea to distributions of fishing. ICES J. Mar. Sci. doi: 10.1093/icesjms/fst185.

Hüssy, K., 2008. Otolith shape in juvenile cod (Gadus morhua): Ontogenetic and environmental effects. J. Exp. Mar. Biol. Ecol. 364, 35-41. 
Hüssy, K., 2010. Why is age determination in Baltic cod (Gadus morhua L.) so difficult? ICES J. Mar. Sci. 67, 1198-1205.

ICES, 2013a. Report of the Herring Assessment Working Group for the Area south of $62^{\circ} \mathrm{N}$ (HAWG). ICES Doc. CM 2013/ACOM:06.

ICES, 2013b. Report of the Baltic Fisheries Assessment Working Group (WGBFAS). ICES Doc. CM 2013/ACOM:10.

Johnson, A.G., Fable Jr., W.A., Grimes, C.B., Trent, L., 1994. Evidence for distinct stocks of king mackerel, Scomberomorus cavalla, in the Gulf of Mexico. Fish. Bul. 92, 91-101.

Jónsdóttir, I.G., Campana, S.E.,Marteinsdottir, G., 2006. Otolith shape and temporal stability of spawning groups of Icelandic cod (Gadus morhua L.). ICES J. Mar. Sci. 63, 1501-1512.

Kuhl, F. P., and Giardina, C. R. 1982. Elliptic features of a closed contour. Comp. Graph. and Image Proc. $18,237-258$.

Lass, H.U., Mohrholz, V., 2003. On dynamics and mixing of inflowing saltwater in the Arkona Sea. J. Geophys. Res. 108(C2), 3042, doi:10.1029/2002JC001465.

Lear, W.H., 1984. Discrimination of the Stock Complex of Atlantic Cod (Gadus morhua) off Southern Labrador and Eastern Newfoundland, as Inferred from Tagging Studies. J. Northw. Atl. Fish. Sci. 5, 143-159.

Lombarte, A., Lleonart, J., 1993. Otolith size changes related with body growth, habitat depth and temperature. Environ. Biol. Fish. 37, 297-306.

Matthäus, W., Franck, H., 1992. Characteristics of major Baltic inflows - A statistical analysis. Cont. Shelf Res. 12, 1375- 1400.

Mérigot, B., Letourneur, Y., Lecomte-Finiger, R., 2007. Characterization of local populations of the common sole Solea solea (Pisces, Soleidae) in the NW Mediterranean through otolith morphometrics and shape analysis. Mar. Biol. 151, 997-1008. 
Messieh, S.N., 1972. Use of Otoliths in Identifying Herring Stocks in the Southern Gulf of St. Lawrence and Adjacent Waters. J. Fish. Res. Bd. Can. 29, 1113-1118.

Mosegaard, H., Madsen, K.P., 1996. Discrimination of mixed herring stocks in the North Sea using vertebral counts and otolith microstructure. ICES CM 1996/H:17, page 1-8

Mosegaard, H,, Svedäng, H., Taberman, K., 1988. Uncoupling of somatic and otolith growth rates in Arctic char (Salvelinus alpinus) as an effect of differences in temperature response. Can. J. Fish. Aquat. Sci. 45, 1514-1524

Nielsen. E.E., Cariani, A., Mac Aoidh, E., Mae, G.E., Milano, I., Ogden, R., Taylor, M., HemmerHansen, J.,Babbucci, M., Bargelloni, L., Bekkevold, D., Diopere, E., Grenfell, L., Helyar, S., Limborg, M.T., Martinsohn, J.T., McEwing, E., Panitz, F., Patarnello, T., Tinti, F., Van Houdt, J.K.J., Volckaert, F.A.M., Waples, R.S., FishPopTrace Consortium, Carvalho, G.R., 2012. Gene-associated markers provide tools for tackling illegal fishing and false ecocertification. Nat. Com. 3: 851, DOI: 10.1038/ncomms1845

Nielsen, E.E., Grønkjær, P., Meldrup, D. and Paulsen, H., 2005. Retention of juveniles within a hybrid zone between North Sea and Baltic Sea Atlantic cod (Gadus morhua). Can. J. Fish. Aquat. Sci. 62, 2219-2225.

Nielsen, E.E., Hansen, M.M., Ruzzante, D.E., Meldrup, D. and Grønkjær, P., 2003. Evidence of a hybrid-zone in Atlantic cod (Gadus morhua) in the Baltic and the Danish Belt Sea revealed by individual admixture analysis. Mol. Ecol. 12, 1497-1508.

Nielsen, B., Hüssy, K., Neuenfeldt, S. Tomkiewicz, J., Behrens, J.W., Andersen, K.H., 2013. Individual behaviour of Baltic cod Gadus morhua in relation to sex and reproductive state. Aquat. Biol. 1, 197-207.

Otterlind, G., 1985. Cod migration and transplantation experiments in the Baltic. J. Appl. Ichthyol. 1, $3-16$. 
Paul, K., Oeberst, R., Hammer, C., 2013. Evaluation of otolith shape analysis as a tool for discriminating adults of Baltic cod stocks. J. Appl. Ichthyol. 29, 743-750.

Petursdottir, G., Begg, G.A. Marteinsdottir, G., 2006. Discrimination between Icelandic cod (Gadus morhua L.) populations from adjacent spawning areas based on otolith growth and shape. Fish. Res. 80, 182-189.

Piry, S., Alapetite, A., Cornuet, J.-M., Paetkau, D., Baudouin, L., and Estoup, A. 2004. GeneClass2: a software for genetic assignment and first-generation migrant detection. Journal of Heredity, 95: 536-539.

Rannala, B., and Mountain, J. L. 1997. Detecting immigration by using multilocus genotypes. Proceedings of the National Academy of Sciences USA, 94: 9197-9201.

Reiss, H., Hoarau, G., Dickey-Collas, M. and Wolff, W. J. 2009. Genetic population structure of marine fish: mismatch between biological and fisheries management units. Fish and Fisheries 10 (4): 361-395.

Reznick D, Lindbeck E, Bryga, H., 1989. Slower growth results in larger otoliths: An experimental test with guppies (Poecilia reticulat). Can. J. Fish. Aquat. Sci. 46, 108-112.

Ruzzante, D.E., Mariani, S., Bekkevold, D., André, C., Mosegaard, H., Clausen, L.A.W., Dahlgren, T.G., Hutchinson, W.H., Hatfield, E.M.C., Torstensen, E., Brigham, J., Simmonds, E.J., Laikre, L., Larsson, L.C., Stet, R.J.M., Ryman, N., Carvalho, G.R., 2006. Biocomplexity in a highly migratory pelagic marine fish, Atlantic herring Proc. R. Soc. B. 273, 1459-1464.

Ruzzante, D.E., Taggart, C.T., and Cook, D., 1999. A review of the evidence for genetic structure of cod (Gadus morhua) populations in the NW Atlantic and population affinities of larval cod off Newfoundland and the Gulf of St. Lawrence. Fish. Res. 43, 79-97.

SAS (r) Proprietary Software 9.4 (TS1M0) Copyright (c) 2002-2012 by SAS Institute Inc., Cary, NC, USA. 
Secor D.H., Dean, J.M., 1989. Somatic growth effects on the otolith - fish size relationship in young pond-reared striped bass, Morone saxatilis. Can. J. Fish. Aquat. Sci. 46, 113-121.

Simoneau, M., Casselman, J.M., and Fortin, R., 2000. Determining the effect of negative allometry (length/height relationship) on variation in otolith shape in lake trout (Salvelinus namaycush), using Fourier-series analysis. Can. J. Zool. 78, 1597-1603.

Stransky, C., Baumann, H., Fevolden, S.-E., Harbitz, A., Høie, H., Nedreaas, K.H., Salberg, A.-B., Skarstein, T. H., 2008. Separation of Norwegian coastal cod and Northeast Arctic cod by outer otolith shape analysis. Fish. Res. 90, 26-35.

Tomkiewicz, J., Tybjerg, L. and Jespersen, Å., 2003. Micro- and macroscopic characteristics to stage gonadal maturation of female Baltic cod. J. Fish Biol. 62, 253-275.

Tracey, S.R., Lyle, J.M., Duhamel, G., 2006. Application of elliptical Fourier analysis of otolith form as a tool for stock identification. Fish. Res. 77, 138-147. 
Table 1 Summary of the sample collection.

\begin{tabular}{llllll}
\hline Stock & Area (SD) & Sample type & Month & n otoliths & n genetics \\
\hline Western & 22 & Spawning & March/April & 410 & 148 \\
Eastern & 25 & Spawning & June/July & 854 & 74 \\
& & Spawning & August & 411 & 14 \\
Unknown & 24 & Spawning & May & 207 & 207 \\
& & Spawning & June/July & 937 & 407 \\
& & Non-spawning & June/July & 121 & 121 \\
\hline Total & & & 2940 & 971 \\
\hline
\end{tabular}


Table 2 Overview over the size stratified subsets selected as calibration samples from the "spawning stock" and "combined" baseline samples. The numbers underneath the SD's identify which area the samples were selected from and the last column shows the subset sample size used for the Discriminant Analyses.

\begin{tabular}{|c|c|c|c|c|c|c|c|}
\hline \multirow[t]{2}{*}{ Baseline } & \multirow[t]{2}{*}{ Stock } & \multirow[t]{2}{*}{ Size group } & \multirow[t]{2}{*}{$\mathrm{n}_{\text {baseline }}$} & \multicolumn{4}{|l|}{$\mathrm{n}_{\text {subset }}$} \\
\hline & & & & SD 22 & SD 24 & SD 25 & Total \\
\hline \multirow[t]{4}{*}{ Spawning } & Western & $<32$ & 0 & - & - & - & - \\
\hline & & $32-39$ & 2 & 1 & - & - & 1 \\
\hline & & $40-47$ & 23 & 20 & - & - & 20 \\
\hline & & $>47$ & 385 & 334 & - & - & 334 \\
\hline \multirow[t]{4}{*}{ Spawning } & Eastern & $<32$ & 316 & - & - & 259 & 259 \\
\hline & & $32-39$ & 579 & - & - & 474 & 474 \\
\hline & & $40-47$ & 278 & - & - & 234 & 234 \\
\hline & & $>47$ & 92 & - & - & 79 & 79 \\
\hline \multirow[t]{4}{*}{ Combined } & Western & $<32$ & 20 & - & 15 & - & 15 \\
\hline & & $32-39$ & 19 & 1 & 13 & - & 14 \\
\hline & & $40-47$ & 33 & 7 & 7 & - & 14 \\
\hline & & $>47$ & 396 & 8 & 8 & - & 16 \\
\hline \multirow[t]{4}{*}{ Combined } & Eastern & $<32$ & 474 & - & 99 & 15 & 114 \\
\hline & & $32-39$ & 842 & - & 99 & 15 & 114 \\
\hline & & $40-47$ & 484 & - & 99 & 15 & 114 \\
\hline & & $>47$ & 142 & - & 35 & 15 & 50 \\
\hline
\end{tabular}


Table 3 Results of the cross-validated self-assignment success of the "spawning stock" baseline.

\begin{tabular}{|c|c|c|c|c|}
\hline Spawning stock & size group & $\mathrm{n}$ & Classification success $(\%)$ & $\operatorname{Bias}(\%)$ \\
\hline \multirow[t]{4}{*}{ Western } & $<32$ & 0 & - & - \\
\hline & $32-39$ & 2 & 100 & 1250 \\
\hline & $40-47$ & 23 & 96 & 213 \\
\hline & $>47$ & 385 & 62 & -35 \\
\hline \multirow[t]{4}{*}{ Eastern } & $<32$ & 316 & 32 & -68 \\
\hline & $32-39$ & 579 & 57 & -43 \\
\hline & $40-47$ & 278 & 81 & -19 \\
\hline & $>47$ & 92 & 90 & 149 \\
\hline
\end{tabular}


Table 4 Genetic validation of classification success of the "mixed stock" samples captured in SD 24 for each of the size groups based on the "spawning stock" baseline and "combined" baseline respectively. Numbers are \% classification success, \% bias and \% classification success after reassignment; $\mathrm{n}=$ number of individuals within each size group.

\begin{tabular}{|c|c|c|c|c|c|c|}
\hline Baseline & Stock & size & $\mathrm{n}$ & Class. success & Bias & $\begin{array}{l}\text { Class. success } \\
\text { after bias correction }\end{array}$ \\
\hline \multirow[t]{4}{*}{ Spawning } & Western & $<32$ & 20 & 100 & 495 & 15 \\
\hline & & $32-39$ & 17 & 100 & 965 & 41 \\
\hline & & $40-47$ & 10 & 80 & 550 & 60 \\
\hline & & $>47$ & 11 & 82 & 36 & 91 \\
\hline \multirow[t]{4}{*}{ Spawning } & Eastern & $<32$ & 158 & 21 & -79 & 99 \\
\hline & & $32-39$ & 263 & 44 & -56 & 96 \\
\hline & & $40-47$ & 206 & 72 & -27 & 92 \\
\hline & & $>47$ & 50 & 87 & -9 & 89 \\
\hline
\end{tabular}

\begin{tabular}{|c|c|c|c|c|c|c|}
\hline \multirow[t]{2}{*}{ Combined } & \multirow[t]{2}{*}{ Western } & $<32$ & 20 & 95 & 150 & 75 \\
\hline & & $32-39$ & 17 & 94 & 271 & 59 \\
\hline \multirow{6}{*}{ Combined } & \multirow{6}{*}{ Eastern } & $40-47$ & 10 & 90 & 180 & 70 \\
\hline & & $>47$ & 11 & 82 & 0 & 82 \\
\hline & & $<32$ & 158 & 75 & -24 & 96 \\
\hline & & $32-39$ & 263 & 84 & -16 & 98 \\
\hline & & $40-47$ & 206 & 91 & -9 & 98 \\
\hline & & $>47$ & 50 & 96 & 0 & 96 \\
\hline
\end{tabular}


Figures

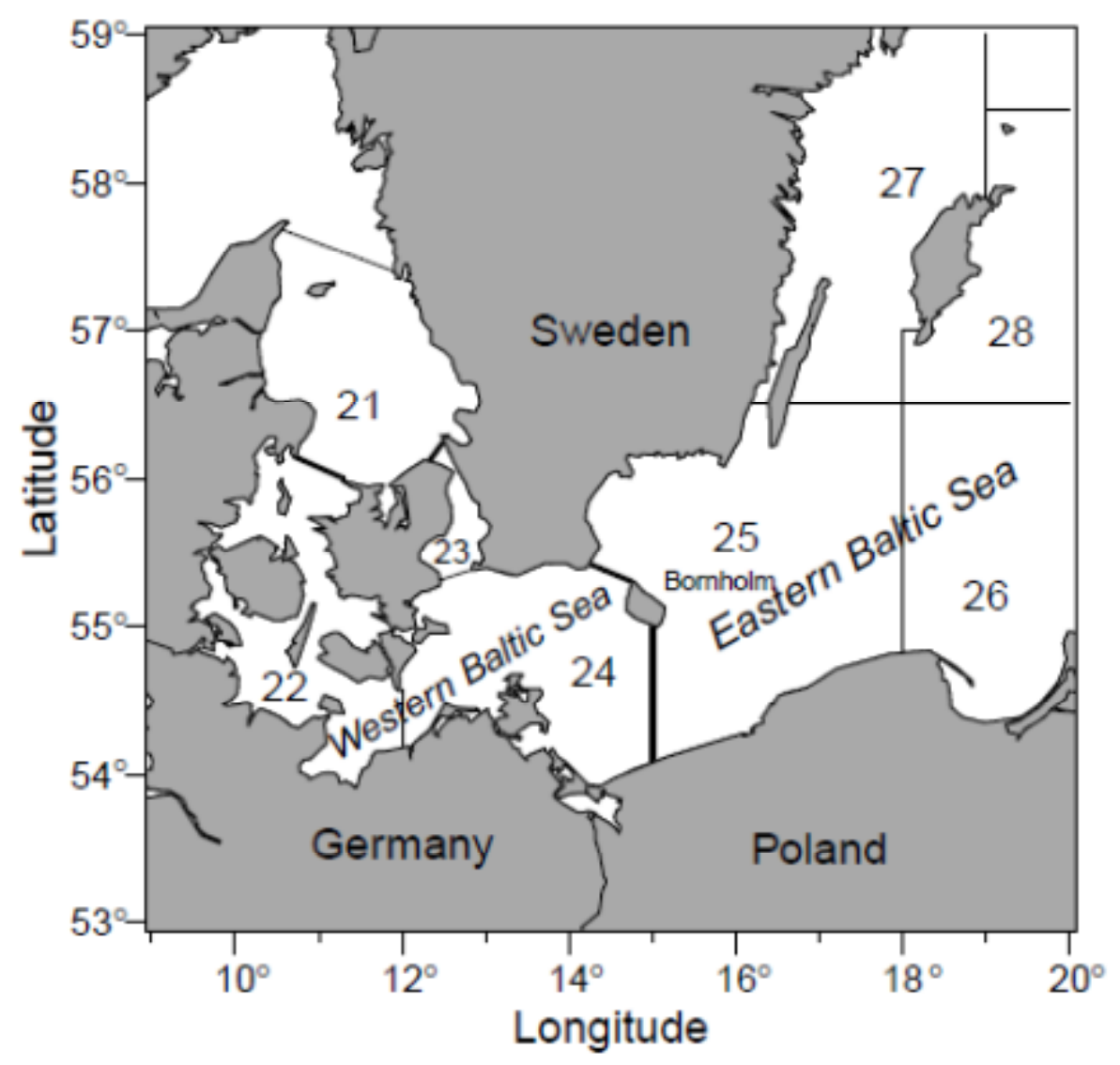

Fig. 1 Map of the Baltic Sea. Numbers indicate ICES subdivisions (SD), thin lines indicate SD boundaries and solid lines the boundaries between the Kattegat, western and eastern Baltic Sea management areas. 


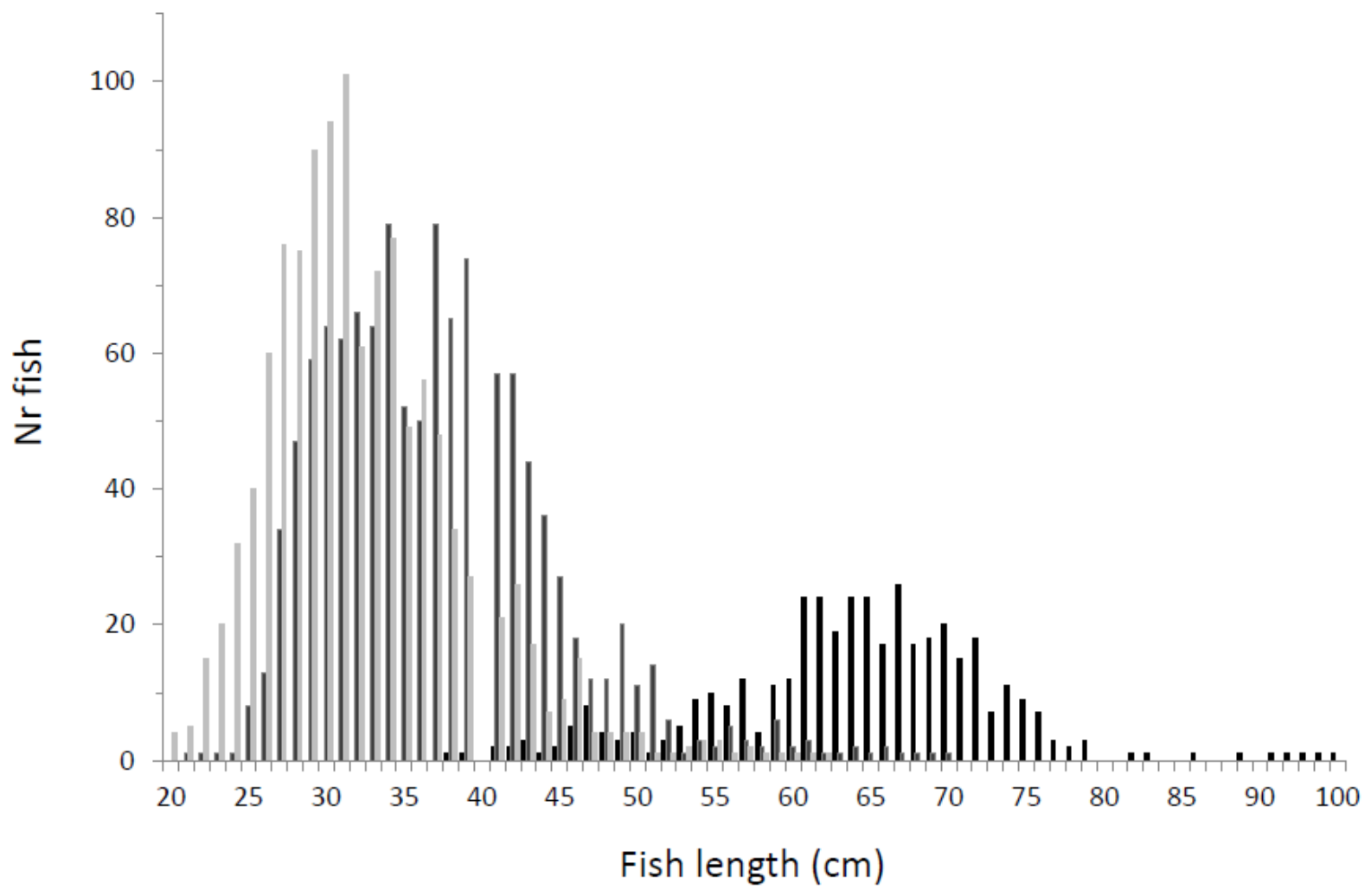

Fig. 2 Length distributions of the samples used. Black $=$ SD 22, dark grey $=$ SD 25, light grey $=$ SD 24. 


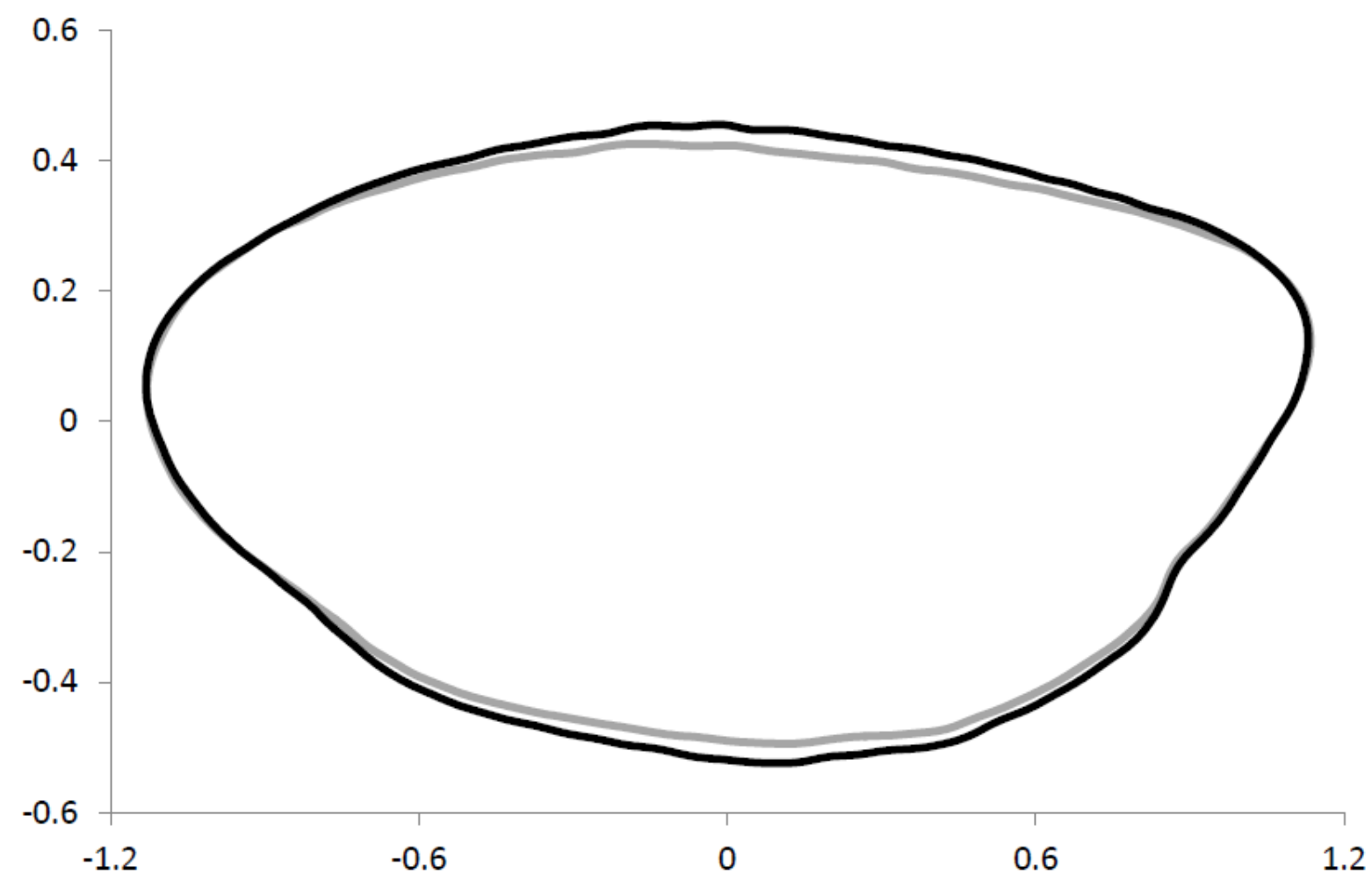

Fig. 3 Otolith outlines of eastern (grey) and western (black) Baltic cod, averaged over all baseline sample individuals in the size class $32-39 \mathrm{~cm}$. 


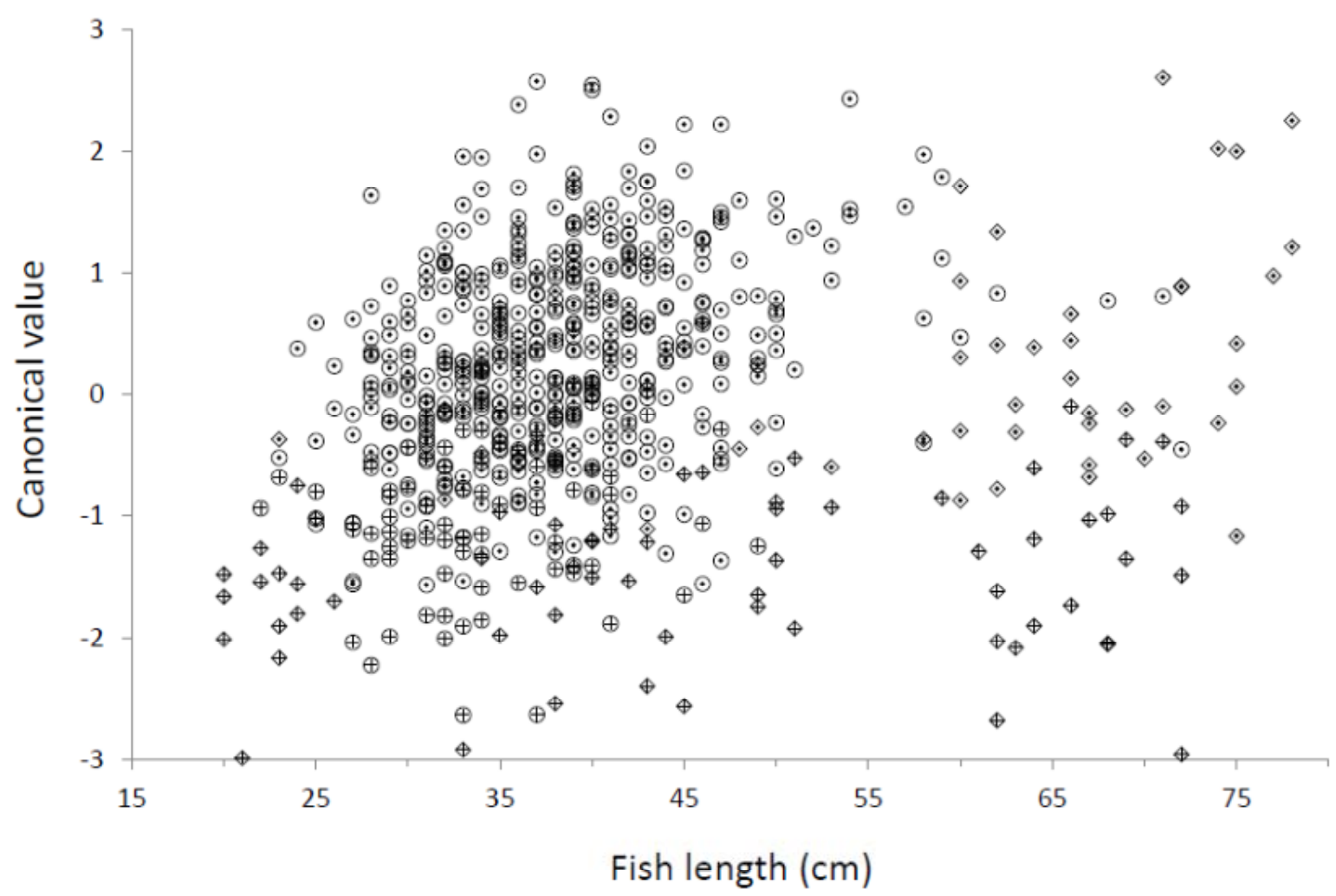

Fig. 4 Scatterplot of classification success of the mixed stock sample using the "combined" baseline. Open symbols represent the genetic assignment of the fish (circles $=\mathrm{SD} 25$, rhomb $=\mathrm{SD} 22$ ) while the symbol inside represents the SD the fish were classified to (dots $=\mathrm{SD} 25$, crosses $=\mathrm{SD} 22)$. The Canonical value is the average of the first canonical value of each the replicate Discriminant Analysis runs. 